\title{
LOS INFINITIVOS ADVERBIALES Y SUS SIGNIFICADOS
}

\author{
Klára Hálková
}

\begin{abstract}
This contrastive analysis examines different infinitive constructions in protasis, their semantic value and their equivalents in Czech language. Using the parallel corpus Intercorp as the main tool we can define Czech equivalents and check if the meanings of the adverbial infinitives agree with the theory.

Keywords: infinitive; contrastive analysis; Spanish; Czech.

Resumen: Este estudio contrastivo examina diferentes construcciones infinitivas en prótasis, su valor semántico y sus equivalentes en checo. Como herramienta principal para delimitar los equivalentes checos y comprobar si los significados de los infinitivos adverbiales están de acuerdo con la teoría, nos sirve el corpus paralelo Intercorp y su rico material lingüístico.
\end{abstract}

Palabras claves: infinitivo; análisis contrastivo; español; checo.

\section{Objetivo del presente artículo}

En este artículo nos centraremos en construcciones infinitivas con diferentes preposiciones en prótasis. Estudiaremos su valor semántico desde el punto de vista teórico y a continuación analizamos los datos adquiridos en el corpus paralelo Intercorp, ${ }^{1}$ que será nuestra herramienta principal. Gracias al corpus también podremos describir qué equivalentes corresponden a estas construcciones en checo.

\section{Los infinitivos adverbiales}

Los infinitivos adverbiales se caracterizan por su plena autonomía semántica con respecto al predicado principal, pueden llevar sujeto expreso, bien sea de forma nominal o pronominal, habitualmente en la posición posverbal. Deben ir precedidos por una marca subordinante que suele ser compatible con un verbo en forma personal, por ejemplo después de, a pesar de, por, para, etc. Nosotros estudiaremos sobre todo las preposiciones que en combinación con el infinitivo adquieren diferentes significados, es decir al, a, con y de. Las gramáticas suelen clasificar los infinitivos a base de criterios semánticos y formales, por lo cual nos encontramos ante dos grupos: los infinitivos temporales, causales, moda-

\footnotetext{
1 El objetivo del proyecto Intercorp consiste en crear un corpus paralelo de veinte idiomas, aprovechando la base de datos del Corpus Nacional Checo. En el momento de la redacción de este artículo, el corpus checoespañol contaba con 82 obras, en su mayoría originales de un idioma u otro, en total 8.427.000 palabras en español que correspondían a 7.210.000 palabras en checo. Para más información, consultar http://www.korpus.cz/intercorp
} 
les y finales que disponen en mayor o menor medida de correlatos, y los infinitivos condicionales, concesivos, comparativos y consecutivos que poseen carácter más periférico.

\section{Al+infinitivo}

Según García Fernández: “Esta construcción indica simultaneidad entre el verbo y el tiempo del evento principal y equivale a cuando con el verbo finito." ${ }^{2}$

Al llegar al hospital, se desmayó.

Este significado es lógicamente el más frecuente y más importante para esta construcción, pero no debe cumplir ni una de las características anteriormente mencionadas, es decir, puede expresar también anterioridad, no tiene que ser idéntica con las construcciones con cuando y puede adoptar otros significados. ${ }^{3}$

$A l+$ infinitivo adopta un significado causal si el verbo del infinitivo expresa estado (y por tanto, no es equivalente a la oración subordinada con cuando). Todos los ejemplos de este artículo provienen de la Gramática Descriptiva de la Lengua Española: ${ }^{4}$

Al ser Pepe de Cáceres, sabe hacer muy bien las migas.

*Cuando Pepe es de Cáceres, sabe hacer muy bien las migas.

En los verbos de estado importa también si el estado ha sido delimitado temporalmente. La oración Al estar Juan en casa, María se fue solamente podemos interpretarla como causal, ya que el tiempo pasado del verbo de la oración principal no se puede interpretar como paralelo a la acción no terminada, expresada por el infinitivo, ni como anterior a ésta. ${ }^{5}$

El significado temporal también se pierde cuando la preposición va acompañada de un infinitivo compuesto o del verbo poder. Al contrario, es compatible con el verbo tener que, lo cual podemos comprobar mediante el pronombre cuándo. Si la respuesta, usando Al+infinitivo, tiene sentido, se trata de significado temporal. ${ }^{6}$

Al haber terminado la partitura, se sintió satisfecho.

¿Cuándo se sintió satisfecho? *Al haber terminado la partitura.

Al poder verlo, se puso muy contento.

¿Cuándo se puso muy contento? *Al poder verlo.

Al tener que confesármelo, se sonrojó.

¿Cuándo se sonrojó? Al tener que confesármelo.

El significado temporal también se excluye en negación y en presencia de ciertos cuantificadores u otros complementos, por ejemplo demasiado, siempre o tan acompañado de adjetivo.

2 Cit. García Fernández, L. (1999), «Los complementos adverbiales temporales. La subordinación temporal», in: Bosque, I. - Demonte, V. Gramática descriptiva de la lengua española, Madrid: Espasa Calpe, p. 3187.

3 Cf. Čermák, P. (2009), Tipología del español actual a la luz de la teoría de Vladimír Skalička, Praha: Karolinum, p. 149.

4 García Fernández, L. (1999), «Los complementos adverbiales temporales. La subordinación temporal», in: Bosque, I. - Demonte, V., Gramática descriptiva de la lengua española; Hernanz, M. L. (1999), «El infinitivo», in: Bosque, I. - Demonte, V., Gramática descriptiva de la lengua española, Madrid: Espasa Calpe.

5 Cit. Čermák, P., Tipología del español actual a la luz de la teoría de Vladimír Skalička, op. cit., p. 149.

6 Cf. García Fernández, L., «Los complementos adverbiales temporales. La subordinación temporal», in: Bosque, I. - Demonte, V., Gramática descriptiva de la lengua española, op. cit., p. 3187. 
Al no comparecer el presidente, se suspendió el debate.

Al acertar siempre Juan las respuestas, Carlos prorrumpió en aplausos.

Al llegar los invitados tan tarde, la cena estaba fría.

En su significado causal, la construcción Al+infinitivo equivale más o menos a las oraciones subordinadas con como, pero a diferencia de ellas "no presenta una causa necesaria u objetiva, sino una apreciación o valoración del hablante, quien establece un desplazamiento metafórico desde el contenido tiempo concomitante de la expresión al+infinitivo hasta la relación nocional causa-efecto." ${ }^{7}$ La presencia de un rasgo semántico temporal y valorativo hace que en la oración principal no pueda aparecer un imperativo. ${ }^{8}$

Como no llamaste, nos fuimos / Al no llamar tú, nos fuimos.

Como no se deciden, vámonos. $/{ }^{*}$ Al no decidirse, vámonos.

Antes de dedicarnos al estudio contrastivo de la construcción Al+infinitivo, veamos qué equivalentes checos puede adoptar. Las lenguas disponen de distintos medios para expresar el segundo mensaje, generalmente se trata de una oración independiente, una oración coordinada, subordinada, de una construcción que carece de verbo en forma personal o del elemento sintáctico. A continuación usaremos la división de Petr Čermák en cuanto a los equivalentes checos de las construcciones no personales en español que pueden adoptar las siguientes formas: ${ }^{9}$

\section{- Una oración principal}

La oración que expresa el segundo mensaje empleando un verbo finito no se subordina a otra oración: se trata de un período coordinado.

Al desnudarme ocupé el costado que daba a la ventana de la pieza.

Svlékl jsem se do slipů a lehl si na stranu k oknu.

\section{- Una oración subordinada}

La oración que expresa el segundo mensaje mediante un verbo finito está subordinada a la oración principal. El checo, una lengua flexiva, emplea este equivalente muy frecuentemente.

De haberlo sabido, quizás habría podido hacer algo.

Kdybych to věděl, možná jsem v tom mohl něco podniknout.

\section{- Una construcción semioracional (transgresivo)}

Esta construcción se usa excepcionalmente en el checo actual.

Al defender la nación defendemos nuestro mañana, no nuestro ayer.

Bráníce svůj národ, bráníme svi̊j zítřek, ne svi̊j včerešek.

7 Cit. Galán Rodríguez, C. (1999), «La subordinación causal y final», in: Bosque, I. - Demonte, V., Gramática descriptiva de la lengua española, Madrid: Espasa Calpe, p. 3620.

8 Cit. Čermák, P., Tipología del español actual a la luz de la teoría de Vladimír Skalička, op. cit., p. 150.

9 Cf. Íbid., p. 150. 


\section{- Un elemento sintáctico}

Aparecen varios subtipos:

a) La base del elemento sintáctico la constituye un sustantivo derivado del equivalente checo del verbo empleado en la construcción española (excepcionalmente también un derivado verbal de otra índole):

Con disculpar no se arregla nada, señora.

Promíjením se nic nespraví, paní.

b) La base del elemento sintáctico la forma un sustantivo relacionado semánticamente con el significado del verbo del segundo mensaje:

De ser así, las consecuencias serán una elección... - V takovém př́padě bude výsledkem volba...

Al pasar vio... - Cestou viděl...

c) La base del elemento sintáctico la constituye otra parte (explícita o implícita) de la construcción española (el agente del segundo mensaje o eventualmente otro complemento de este verbo):

Al salir volví a oír el ladrido del perro... - Venku jsem opět zaslechl štěkot psa ...

\section{- Otra forma}

Incluimos en este tipo poco frecuente todos los casos traducidos de una manera diferente de los que describimos en los tipos 1-4 (a veces, el traductor no ha traducido la construcción):

De ser así, entonces Rusia puede olvidarse de lograr el rápido...

Rusko by pak mohlo zapomenout na to, že dosáhne rychlého...

Según lo arriba comentado, nuestro análisis trata de construcciones infinitivas semipredicativas en prótasis. En el corpus paralelo la construcción Al+infinitivo apareció en 1657 casos, de lo cuales 18 estaban en negación. Veamos en la tabla la distribución de los equivalentes checos:

\begin{tabular}{|c|c|c|}
\hline Equivalente checo & Número de apariciones & $\%$ \\
\hline Oración principal & 127 & 7,7 \\
\hline Oración subordinada & 901 & 54,4 \\
\hline Transgresivo & 4 & 0,2 \\
\hline Elemento sintáctico & 530 & 32 \\
\hline Otra forma & 95 & 5,7 \\
\hline
\end{tabular}

Los equivalentes checos más frecuentes son, como era de esperar, las oraciones subordinadas y los elementos sintácticos que en total representan más del $86 \%$ de todos los equivalentes. La oración subordinada en sí equivale a más del $54 \%$ del total de los equivalentes. La escasísima aparición de los transgresivos checos se debe a la composición del corpus Intercorp, pues está compuesto en su mayoría por textos escritos durante los últimos cuarenta años. 
Los infinitivos adverbiales y sus significados

\begin{tabular}{|c|c|c|}
\hline Locución conjuntiva & Número de apariciones & $\%$ \\
\hline Když & 631 & 70 \\
\hline Jak & 56 & 6,2 \\
\hline Jakmile & 36 & 4 \\
\hline Tím, že & 29 & 3,2 \\
\hline
\end{tabular}

En los equivalentes checos expresados por una oración subordinada prevalece absolu-

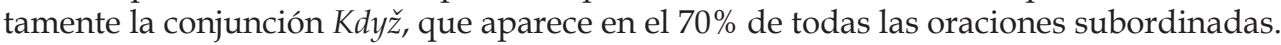

Ya hemos delimitado las reglas que una construcción debe cumplir para expresar un significado adverbial concreto. El temporal es, como cabía esperar, el más frecuente. Veamos la distribución:

\begin{tabular}{|c|c|c|}
\hline Significado del infinitivo & Número de casos & $\%$ \\
\hline Tiempo & 1441 & 87 \\
\hline Causa & 81 & 4,8 \\
\hline Condición & 56 & 3,4 \\
\hline Modo & 3 & 0,2 \\
\hline Otro (significado no adverbial) & 76 & 4,6 \\
\hline
\end{tabular}

Antes de evaluar los resultados, hemos de recalcar que no siempre hemos determinado el significado de la construcción partiendo del equivalente checo, en casi el $6 \%$ de los casos la traducción no correspondía al original. Según esperamos, el significado temporal es de predominancia absoluta con el $87 \%$ de todos los casos, al significado causal le corresponde el 4,8\%. Las construcciones en negación -18 apariciones - llevaban, de acuerdo con la teoría, el significado causal. Según la teoría el significado temporal de Al+infinitivo se excluye en combinación con los verbos de estado (ser, estar) o con el infinitivo compuesto. Notamos 14 ocurrencias del verbo ser en esta construcción, tratándose de causa en 6 casos y de tiempo en 8 casos. Aun así no hay conflicto, en construcciones temporales el verbo ser formaba parte de la voz pasiva. Al+estar expresaba en 4 casos una causa, en 1 una condición. El infinitivo compuesto apareció 8 veces, en 5 casos, sin duda alguna, como causal, en un caso la construcción no fue traducida. Los dos casos restantes son discutibles. A pesar de que los equivalentes checos expresan tiempo, en nuestra opinión pueden interpretarse como causa. ${ }^{10}$ Suponemos que estos casos se deben

Jakmile Kaczyński odmítl jako svého partnera Občanskou platformu, rozhodl se spojit svou menšinovou PiS s populistickou stranou Sebeobrana a nacionalistickou LPR .

Poté, co utrpěly přerušeními dodávek plynu a ropy, k nimž došlo po roztržkách mezi Ruskem a Ukrajinou a poté Běloruskem, členské státy EU konečně pochopily, že jejich přežití závisí na schopnosti diverzifikovat své energetické zdroje.
Al haber rechazado a la Plataforma Cívica como socio, Kaczynski decidió aliar su minoritario PiS con el populista Partido de Autodefensa y el nacionalista LPR.

Al haber sufrido interrupciones en los suministros de petróleo y gas después de las disputas entre Rusia y Ucrania y luego Bielorrusia, los miembros de la UE finalmente entendieron que su supervivencia depende de su capacidad para diversificar sus fuentes energéticas. 
a una traducción no precisa. El significado condicional contó con 56 apariciones, pero en ciertos casos era prácticamente imposible distinguir con seguridad una condición del significado temporal. El significado modal fue representado por 3 ocurrencias, pero mezclado semánticamente con una delimitación temporal. Como ejemplo de construcción infinitiva de significado no adverbial sírvanos Al parecer. El verbo parecer es el tercero con más ocurrencias en esta construcción, en checo expresado en $68 \%$ de los casos con un elemento sintáctico (en concreto con žrejmě, očividně, údajně, patrně), en $26 \%$ de los casos con una oración subordinada encabezada por zdá se. Dado un número considerable de las apariciones de esta construcción, para una comparación la incluimos en la tabla referente a los significados como "no adverbial". Hemos de señalar que si hubiéramos excluido las construcciones lexicalizadas de nuestro análisis, los resultados de los porcentajes de los significados serían diferentes.

\section{A+infinitivo}

La construcción A+infinitivo habitualmente lleva en español dos significados predominantes: condicional y modal. En caso del significado condicional se trata de construcciones fosilizadas, como a no ser (que), a decir verdad, a juzgar por, a poder ser, a ser posible. Según la Gramática Descriptiva, su empleo fuera de estos casos se halla muy restringido en la lengua actual, tanto en España como en América. ${ }^{11}$ Con el significado modal de esta construcción nos encontramos en las locuciones adverbiales de modo, muy a menudo lexicalizadas, por ejemplo aplaudir a rabiar, tirar a matar, etc. Una variante característica de estas expresiones se forma con la incorporación del cuantificador todo, como salir a todo correr, llorar a todo llorar, etc. En situaciones muy concretas la construcción adquiere el significado final. Es característico que la preposición determina tanto el verbo principal, como el infinitivo. El verbo principal suele expresar movimiento o su detención. Esta construcción no admite la negación ante el infinitivo.

Acudieron a ver el espectáculo.

Se levantaron a apagar el fuego.

*Se sentaron a no ver el espectáculo.

La construcción A+infinitivo en prótasis tuvo 220 apariciones en el corpus paralelo, sin embargo, para nuestros fines, es decir, análisis de los infinitivos adverbiales, servirán solamente 86 de ellos.

\begin{tabular}{|c|c|c|c|c|c|}
\hline \multirow{5}{*}{ Total verbos } & \multirow{5}{*}{220} & Valencial & 18 & & \\
\hline & & Exclamativo & 2 & & \\
\hline & & \multirow{3}{*}{ Imperativo } & \multirow{3}{*}{114} & A saber & 9 \\
\hline & & & & A ver & 96 \\
\hline & & & & Otros & 9 \\
\hline
\end{tabular}

En la tabla podemos ver la distribución funcional de la construcción estudiada. 18 casos eran de carácter valencial, siempre con referencia a la oración anterior siguiéndola con

${ }_{11}$ Cf. Hernanz, M. L., «El infinitivo», in: Bosque, I. - Demonte, V., Gramática descriptiva de la lengua española, op. cit., p. 2320. 
la construcción infinitiva. ${ }^{12}$ El modo imperativo apareció en 114 casos. En este grupo incluimos la construcción lexicalizada $A$ ver, que con sus 96 casos presenta casi la mitad de todas las apariciones de la preposición a seguida de infinitivo. Mencionamos que para $A+i n f i n i t i v o$ son típicas las locuciones adverbiales, lo cual podemos, gracias a este estudio, confirmar. No se trata solamente del mencionado A ver, sino también de A juzgar por, A decir verdad, etc. El verbo ser, por ejemplo, casi exclusivamente formaba parte de la locución $A$ no ser (que). De los 86 casos analizados, 12 estuvieron en forma negativa.

Veamos la distribución de los equivalentes checos partiendo de la traducción de los casos en la parte española del corpus paralelo.

\begin{tabular}{|c|c|c|}
\hline Equivalente checo & Número de apariciones & $\%$ \\
\hline Oración principal & 15 & 17,5 \\
\hline Oración subordinada & 35 & 40,7 \\
\hline Transgresivo & 0 & 0 \\
\hline Elemento sintáctico & 29 & 33,7 \\
\hline Otra forma & 7 & 8,1 \\
\hline
\end{tabular}

En caso de esta construcción, la oración subordinada y el elemento sintáctico son los equivalentes mayormente empleados, en total presentan más de $74 \%$. Dada la gran variedad de formas de traducciones, no vamos a concretar locuciones conjuntivas, salvo el equivalente de la construcción $A$ juzgar por que en la versión checa fue traducido la mayoría de veces como Soudě podle. El equivalente checo expresado por una oración principal no es con su $15 \%$ muy frecuente, sin embargo, es interesante que en la mayoría absoluta de los casos se trató de infinitivos finales (a diferencia de los infinitivos condicionales que en checo equivalían a una oración subordinada o elemento sintáctico). Dado el volumen de los datos y el uso de gerundios en checo hoy en día, su ausencia no es sorprendente.

Aquí los resultados en cuanto al significado de los casos estudiados:

\begin{tabular}{|c|c|c|}
\hline Significado del infinitivo & Número de casos & $\%$ \\
\hline Condición & 18 & 20,9 \\
\hline Finalidad & 26 & 30,2 \\
\hline Otro (significado no adverbial) & 42 & 48,8 \\
\hline
\end{tabular}

Casi el $70 \%$ de los infinitivos analizados lo representaron las locuciones adverbiales A juzgar por, A no ser (que), o A decir verdad, lo cual confirma la teoría de la Gramática Descriptiva acerca del uso de esta construcción. En cuanto al significado, el condicional representa $20,9 \%$ con las locuciones arriba mencionadas. Del grupo hemos excluido la construcción A juzgar por (con sus 48,8\%) que en nuestra opinión y dado su alto grado de lexicalización, carece del significado adverbial. El 30\% restante lo representan los infiniti-

Byl připraven uznat své omyly, pokud nějaké spáchal. Zpytovat svědomí. Zaplatit za své chyby, pakliže nějaké jsou. Ale at' mu vůdce dá alespoň pět minut.
Estaba dispuesto a reconocer sus errores, si los había cometido. A hacer un examen de conciencia. A pagar sus faltas, si existían. Pero que el jefe le concediera cinco minutos, al menos. 
vos finales que en el corpus solían seguir semánticamente al verbo de la oración anterior, como venir, llegar, salir, irse, pero también llamar y quedarse. No hubo ninguna aparición de los infinitivos modales.

\section{De+infinitivo}

Esta construcción adquiere dos significados: condicional y causal. De todas las construcciones infinitivas, ésta es la más empleada para expresar una condición. Al igual que sucede con las subordinadas finitas encabezadas por el nexo si, la correlación de los tiempos determina la lectura real, potencial o irreal de tales construcciones. ${ }^{13}$

De no venir tú, tampoco iré yo.

De hallar los tesoros, él disfrutaría de una buena parte.

De haberlo sabido, me hubiera / habría quedado en casa.

Es de destacar que la frecuencia del uso de la construcción De+infinitivo es, respecto a la conjunción $\mathrm{Si}$ en una oración subordinada, mucho más baja. La diferencia principal entre las subordinadas finitas y construcciones infinitivas descansa en la apódosis, como lógica consecuencia de la defectividad morfológica del infinitivo, que sólo dispone de dos formas - simple y compuesta - con las cuales plasma en la prótasis la condición real o irreal. ${ }^{14}$ La importancia de los factores temporales en la determinación del valor condicional no dimana solamente de la escasez de rasgos morfológicos del infinitivo, sino también de las características de la preposición de en sí. Dada su polivalencia, requiere elementos formales suplementarios para poder ser interpretada de acuerdo con el significado intencional. En los siguientes ejemplos vemos que para distinguir el infinitivo causal del condicional, el único factor importante es la forma verbal de la oración principal.

De tomar el sol tantas horas, cogió una insolación. (causa)

De tomar el sol tantas horas, cogería una insolación. (condición)

Otros aspectos importantes son la entonación, en la forma oral, y la expresión gráfica de pausas, en la escrita. En ciertos casos es la única manera de diferenciar el significado condicional del causal.

Te habrían acusado, de haberlo dicho. (Te habrían acusado si lo hubieras dicho.)

Te habrían acusado de haberlo hecho. (Te habrían acusado de ello.)

A diferencia de las oraciones subordinadas encabezadas por Si, la construcción De+infinitivo se caracteriza por ciertas restricciones semánticas relacionadas con las denominadas "periféricas". Éstas no expresan hipótesis en sí, sino una aserción encubierta, vinculada con la enunciación. Este tipo de construcción no admite la forma De+infinitivo.

Si tienes hambre, hay un restaurante cerca de casa.

*De tener tú hambre, hay un restaurante cerca de la casa.

Si me dejáis opinar, este viaje está mal organizado.

*De dejarme opinar, este viaje está mal organizado.

\footnotetext{
${ }^{13}$ Hernanz, M. L., «El infinitivo», in: Bosque, I. - Demonte, V., Gramática descriptiva de la lengua española, op. cit., p. 2320.

${ }^{14}$ Cf. Íbid., p. 2320.
} 
Los infinitivos adverbiales y sus significados

El carácter aspectual del infinitivo se caracteriza por la ausencia de la perfectividad de la acción, por tanto, la prótasis de forma no finita es de carácter hipotético. Por esta razón no pueden emplearse en las construcciones condicionales de alegación oculta.

Si la madre es mala, la hija es peor.

*De ser la madre mala, la hija es peor.

Si Ricardo te hace llorar es porque te quiere.

*De hacerte llorar Ricardo es porque te quiere.

La construcción De+infinitivo no resulta natural en el contexto general de la condición, expresada habitualmente por el modelo Si+presente+presente o Si+imperfecto+imperfecto, debido al carácter estrictamente hipotético de ésta. ${ }^{15}$

Si llueve, se mojan las calles. / ?? De llover, se mojan las calles.

Si llegábamos tarde a casa, nos reñían. / ?? De llegar tarde a casa, nos reñian.

El significado casual de la construcción De+infinitivo es, en comparación con el condicional, menos frecuente en cuanto al uso. La preposición suele estar seguida del cuantificador tan o tanto, pero no necesariamente.

A mí me dolian las piernas de estar arrodillado.

Les salieron ampollas en los pies de tanto caminar.

Los ojos me dolian de tenerlos tan redondos, tan fijos y tan desorbitados.

La oración principal puede entenderse como efecto, cuya causa está abarcada en el infinitivo, o como consecuencia de la realidad expresada por el infinitivo.

Se ha quedado afónica de tanto gritar.

Se ha quedado afónica porque gritaba mucho. / Grita tanto que se ha quedado afónica.

Hemos de mencionar que esta construcción representa mayores restricciones que Por+infinitivo, por tanto, no se pueden alternar libremente (cf. *No puede conducir de ser menor de edad.).

La construcción De+infinitivo apareció en el corpus paralelo en 99 casos, de los cuales 13 fueron de carácter valencial. Estos casos los excluimos del estudio referente a los equivalentes checos y significado del infinitivo. De los 86 casos restantes 32 fueron representados por una negación.

Centrémonos en la distribución de los equivalentes checos:

\begin{tabular}{|c|c|c|}
\hline Equivalente checo & Número de apariciones & \% \\
\hline Oración principal & 1 & 1,1 \\
\hline Oración subordinada & 65 & 75,6 \\
\hline Transgresivo & 0 & 0 \\
\hline Elemento sintáctico & 11 & 12,8 \\
\hline Otra forma & 9 & 10,5 \\
\hline
\end{tabular}

${ }^{15}$ Cf. Montolío, E., «Las construcciones condicionales», in: Bosque, I. - Demonte, V., Gramática descriptiva de la lengua española, Madrid: Espasa Calpe, p. 3691. 
Igual que en construcciones tratadas anteriormente, en el caso de De+infinitivo también prevalece la oración subordinada, que junto al elemento sintáctico presentan más del $88 \%$ de todos los equivalentes traducidos. En cuanto a locuciones conjuntivas que encabezan la oración subordinada, en checo prevalece claramente Kdyby (27 ocurrencias), seguida de Nebýt (18 ocurrencias) y la conjunción Pokud (8 ocurrencias).

Veamos los significados del infinitivo:

\begin{tabular}{|c|c|c|}
\hline Significado del infinitivo & Número de casos & $\mathbf{\%}$ \\
\hline Condición & 79 & 91,9 \\
\hline Causa & 6 & 7 \\
\hline Finalidad & 1 & 1,1 \\
\hline
\end{tabular}

De los 86 casos analizados, 79 expresaban una condición, es decir, casi el 92\%. En el 52\% se trataba de una condición irreal. Un 7\% lo formaban los casos de significado causal. Un caso resultó ambiguo de clasificar con respecto a su significado, bien final, bien casual. ${ }^{16}$

\section{Con+infinitivo}

La preposición con, seguida de infinitivo, puede tener un significado condicional, concesivo, causal o modal. Esta construcción suele emplearse en la forma escrita del idioma. Con+infinitivo a diferencia de De+infinitivo, puede ir acompañada en su significado condicional del nexo que y una forma verbal en subjuntivo, habitualmente cuando el sujeto de la oración principal no coincide con el de la oración subordinada.

Con entristecerte y llorar, no ganarás nada.

Con que te entristezcas y llores, tu bebé no ganará nada.

El valor condicional lo fija la forma verbal en apódosis, o bien futuro, o bien condicional potencial.

Con hacer las cosas a la brava, no ganaste nada. (Porque hiciste las cosas a la brava...)

Con hacer las cosas a la brava, no ganarás nada. (Si haces las cosas a la brava...)

Si la construcción Con+infinitivo se refiere al pasado, siempre la interpretamos como causal. En consecuencia consideramos el uso del infinitivo compuesto en significado condicional como impertinente, pues el aspecto perfectivo de esta forma verbal supone la referencia al pasado. ${ }^{17}$

*Con haber hecho las cosas a la brava, no habrías ganado nada.

Pese al posible empleo del condicional en la oración principal, la construcción Con+infinitivo, a diferencia de De+infinitivo, no es del todo adecuada para expresar una condición potencial.

16

Abych neměl jen jedny rozbité boty a jednu sadu prádla, kterou jsem nosil, než mi vyprali tu druhou, koupila mi matka nové oblečení a $\mathrm{k}$ tomu kufr velký jako katafalk, nepočítala ovšem s tím, že za př́štích šest měsíců o celou píd' vyrostu. De no tener sino un par de zapatos rotos y una
muda de ropa que usaba mientras me lavaban
la otra, mi madre me equipó de ropa nueva con
un baúl del tamaño de un catafalco sin prever
que en seis meses ya habría crecido una cuarta.

${ }^{17}$ Cf. Montolío, E., «Las construcciones condicionales», in: Bosque, I. - Demonte, V., Gramática descriptiva de la lengua española, op. cit., p. 3693. 
Generalmente se adopta la idea de que entre estas dos construcciones existe cierto tipo de distribución complementaria relacionada a la cuestión de la condición. ${ }^{18}$

??Con hacer las cosas a la brava, no ganarías nada.

De hacer las cosas a la brava, no ganarías nada.

??Con estudiar más, podrías aprobar

De estudiar más, podrías aprobar.

La preposición con, seguida de infinitivo, es una de las pocas que pueden adquirir un significado concesivo.

Con ser tan ricos, viven miserablemente.

En Madrid, con ser la capital, nadie ha hecho nada.

Partiendo de los ejemplos, la prótasis concesiva expresa hechos (no suposiciones) en relación a la forma verbal en presente en la apódosis. Para expresar anterioridad con respecto a la información en la oración principal, puede usarse el infinitivo compuesto.

Con haber sido importante la pérdida de dinero por las dichosas huelgas, ahora lo es más la de tiempo, pues no veo ningún interés en llegar a un acuerdo.

El significado puede resultar ambiguo, cuando la oración se refiere al futuro. En tal caso interpretamos la construcción o bien como condición, o bien como concesión, dependiendo del contexto de la situación. ${ }^{19}$ En el lenguaje hablado nos encontramos muy a menudo con la construcción concesiva Con todo+infinitivo o su variante Con +infinitivo...y todo. ${ }^{20}$

Con todo y ser pobre, hacemos por la enferma cuanto podemos.

Con ser español y todo, no entiende a Góngora.

Según los datos adquiridos, la construcción adverbial Con+infinitivo en prótasis apenas suele emplearse. En todo el corpus paralelo solamente encontramos 6 casos, de los que 1 era de carácter valencial. Dada la escasez de datos es imposible sacar conclusiones relevantes. Solamente mencionaremos que la preposición Con en 4 casos iba acompañada del infinitivo decir, en tres de ellos con el pronombre te. Con respecto al significado de esta construcción, los resultados están de acuerdo con la teoría, es decir prevalece la condición (4 casos) y la concesión aparece 1 vez.

\section{Conclusiones}

El objetivo de este artículo fue estudiar diferentes construcciones infinitivas en prótasis, concretamente, la frecuencia de los condensores en español en combinación con las preposiciones $a l, a, d e, c o n$, sus equivalentes en checo y la proporción de diferentes significados de cada construcción. Como esperado, los equivalentes más empleados de todas las construcciones infinitivas en checo son la oración subordinada y el elemento sintáctico.

Con respecto a los significados y partiendo de los resultados obtenidos, podemos constatar que en su mayoría coinciden con la teoría. Nuestra herramienta principal ha sido el corpus paralelo Intercorp, una base de datos única de su género. A pesar de su

18 Cf. Íbid., p. 3693.

19 Cf. Flamenco García, L., «Las construcciones concesivas y adversativas», in: Bosque, I. - Demonte, V., Gramática descriptiva de la lengua española, op. cit., p. 3852.

${ }^{20}$ Cf. Hernanz, M. L., «El infinitivo», in: Bosque, I. - Demonte, V., Gramática descriptiva de la lengua española, op. cit., p. 2324 
gran utilidad debemos mencionar ciertos inconvenientes afrontados. Uno de ellos es la imposibilidad de averiguar directamente la fuente de los ejemplos. Decidimos trabajar con todos los textos accesibles en checo y español, entre ellos textos originales de terceras lenguas. Por tanto, creemos que los pocos casos que difieren de la teoría con respecto al significado se deben más bien a una traducción errónea.

Las construcciones infinitivas lexicalizadas, carentes de significado adverbial, influyeron en mayor o menor medida los resultados referentes al significado. Analizando la construcción Al+infinitivo, nos encontramos ante la forma lexicalizada Al parecer. En la tabla se refleja como „otro significado“ y está incluido en los resultados con el objetivo de poder observar qué porcentaje representa este tipo de construcciones. Asimismo debemos mencionar que si las hubiéramos excluido estrictamente, los resultados respecto al porcentaje serían diferentes. En caso de A+infinitivo fue más complicado delimitar el grado de la lexicalización de diferentes formas, como por ejemplo $A$ no ser que o A decir verdad. Las consideramos semilexicalizadas, a diferencia de $A$ juzgar por que ha perdido del todo su significado adverbial y podemos confirmar que la construcción A+infinitivo en prótasis aparece casi exclusivamente en las construcciones semilexicalizadas o lexicalizadas. En cambio, las construcciones De+infinitivo y Con+infinitivo mantienen su significado adverbial sin aparencias de las formas lexicalizadas.

\title{
Bibliografía
}

Bosque, Ignacio - Demonte, Violeta (1999), Gramática descriptiva de la lengua española, Madrid: Espasa Calpe.

ČERMÁK, Petr (2009), Tipología del español actual a la luz de la teoría de Vladimír Skalička, Praha: Karolinum.

FLAMENCO GARCíA, Luis (1999), «Las construcciones concesivas y adversativas», in: Boseue, Ignacio - Demonte, Violeta, Gramática descriptiva de la lengua española, Madrid: Espasa Calpe, 3805-3878.

Galán RodrígueZ, Carmen (1999), «La subordinación causal y final», in: BosQue, Ignacio - Demonte, Violeta, Gramática descriptiva de la lengua española, Madrid: Espasa Calpe, 3597-3642.

García FernándeZ, Luis (1999), «Los complementos adverbiales temporales. La subordinación temporal», in: BosQue, Ignacio - DEMONTE, Violeta, Gramática descriptiva de la lengua española, Madrid: Espasa Calpe, 3129-3208.

Hernanz, María Lluisa (1999), «El infinitivo», in: Bosque, Ignacio - Demonte, Violeta, Gramática descriptiva de la lengua española, Madrid: Espasa Calpe, 2198-2356.

Montolío, Estrella (1999), «Las construcciones condicionales», in: BosQue, Ignacio - Demonte, Violeta, Gramática descriptiva de la lengua española, Madrid: Espasa Calpe, 3643-3737.

Páginas web:

<http://ucnk.ff.cuni.cz/intercorp/>

\author{
Klára Hálková \\ Ústav románských studií \\ Filozofická fakulta \\ Univerzita Karlova v Praze \\ Náměstí Jana Palacha 2 \\ 11000 Praha 1 \\ República Checa \\ klara.halkova@seznam.cz
}

